\title{
Las mariposas y el fuego: \\ la mirada de Ricardo Palma sobre \\ cuatro mujeres ecuatorianas ${ }^{1}$
}

Por Gabriela Falconí Piedra

l Varias reflexiones planteadas en el presente texto se desprenden de la investigación que he realizado sobre la vida y obra de Marietta de Veintemilla. FALCONÍ, Gabriela. LA VOZ DETRÁS DEL SILENCIO. Interpelación al discurso oficial del siglo XIX desde Páginas del Ecuador de Marietta de Veintemilla. Lima, Tesis para obtener el grado académico de magíster en Literatura Peruana y Latinoamericana, Universidad Nacional Mayor de San Marcos, 2013. 
Licenciada en Psicología y Ciencias Políticas por la Universidad Central del Ecuador, magíster en Literatura Peruana y Latinoamericana por la UNMSM y especialista en Industrias Culturales y Cooperación Internacional. 
El interés por la estrecha relación que han mantenido Ecuador y Perú, más allá de los distanciamientos políticos y diplomáticos que no afectaron la comunicación entre ambos países, nació durante mis estudios de maestría y me acompañó en los años posteriores. En el ámbito literario, me incliné por los temas que podrían dar cuenta de aquellas conexiones binacionales y, quizá por ello, en el presente trabajo me he abocado a indagar cómo en sus textos Ricardo Palma delinea el perfil de cuatro mujeres ecuatorianas: Rosa Campusano, Manuela Sáenz, Dolores Veintimilla de Galindo y Marietta de Veintemilla; y cómo dos de ellas, Manuela y Marietta, desafiaron al rol prefigurado para las mujeres en el siglo XIX en América Latina, incursionando en el ámbito público que estaba destinado al quehacer masculino: las letras y la política.

Como sostiene Oswaldo Holguín, no fueron pocos los hijos del Ecuador que estuvieron por estar tierras y que Palma conoció en diversas etapas de su vida y por distintas razones ${ }^{2}$. Algunos de ellos, como lo demuestra José Miguel Vásconez ${ }^{3}$, se han vuelto personajes de las Tradiciones Peruanas como es el caso de Rosa Campusano y Manuela Sáenz.

2 HOlguín CAllo, Oswaldo. Páginas sobre Ricardo Palma. Lima, Universidad Ricardo Palma, 2001, p. 82.

3 VÁSCONEZ, José Miguel. "El Ecuador en las Tradiciones de Ricardo Palma”, pp. 285 - 323. En: Instituto Ricardo Palma. Aula Palma VI. Lima, Universidad Ricardo Palma, 2007. 
Llamada "La Protectora" por la relación que se le adjudicaba con San Martín, la guayaquileña Rosa Campusano(1798 - 1860) es descrita por Palma en dos tradiciones como una "señora que frisaba en los cincuenta, de muy simpática fisonomía, delgada, de mediana estatura, color casi alabastrino, ojos azules y expresivos, boca pequeña y mano delicada. Veinte años atrás debió haber sido mujer seductora por su belleza y gracia y trabucado el seso a muchos varones en ejercicio de su varonía" 4 . Los atributos físicos y la educación de La Protectora, quien fuera además madre de su compañero de colegio, Alejandro Weniger, son resaltados por Palma con cierta picardía cuando describe la justa condecoración de la "Orden del Sol" que le fue entregada por ser una decidida partidaria y servidora de la Independencia. Es seguro que a ninguna otra de las caballerescas debió la causa libertadora servicios de tanta magnitud como los prestados por doña Rosa. En la hora de la recompensa y de los honores, no era lícito agraviarla con ingrato olvido. (Palma: 2004, 11).

Los atributos que caracterizan a La Protectora son claramente contrapuestos por el tradicionista con aquellos que utiliza para describir a Manuela Sáenz (1796-1859):

La protectora amaba el hogar y la vida de la ciudad y La Libertadora se encontraba como en su centro en medio de la turbulencia de los cuarteles y del campamento. La primera nunca paseó sino en calesa. A la otra se la vio en las calles de Quito y en las de Lima cabalgada a manera de hombre en brioso corcel, escoltada por dos lanceros de Colombia y vistiendo dilmán rojo con brandeburgos de oro y pantalón bombacho de cotonia blanca. (Palma: 2004, 13).

4 PALMA, Ricardo. Tradiciones peruanas. Lima, Universidad Ricardo Palma Diario La República, Tomo VIII, 2004, p. 7. 
Y es que Manuela Sáenz, a quien llamaron "La Libertadora" por su innegable apoyo a la Independencia, fue la autora de una gran correspondencia donde se observa el contexto de las luchas libertarias y el horizonte buscado a través de ellas. Bajo la sombra del Libertador Simón Bolívar, Manuela fue al mismo tiempo admirada y acusada por su templanza varonil, como refiere el mismo Ricardo Palma en una de sus tradiciones, escrita a propósito del encuentro que tuvo con ella en el puerto de Paita en 1856, cuando era "una señora de abundantes carnes, ojos negros y animadísimos, en los que parecía reconcentrado el resto del fuego vital que aún le quedara" (Palma: 2004, 13) como "mujer superior acostumbrada al mando y a hacer imperar su voluntad" (Palma: 2004,14). Como es de suponer, Manuela le inspiró al tradicionista un respetuoso sentimiento de amistad que no disminuyó la severidad de sus juicios al no encontrar en ella el perfil femenino esperado:

Era una equivocación de la naturaleza, que en formas esculturalmente femeninas encarnó espíritu y aspiraciones varoniles. No sabía llorar, sino encolerizarse como los hombres de carácter duro. (...) Leía a Tácito y a Plutarco; estudiaba la historia de la Península en el padre Mariana, y la de América en Solís y Garcilaso; era apasionada de Cervantes, y para ella no había poetas más allá de Cienfuegos, Quintana y Olmedo. (Palma: 2004, 18).

Y es que tanto para la sociedad limeña como para los habitantes de la ciudad de Quito, que la vieron sobre "un potro color jaspeado, con montura de hombre, pistoleras al arzón y gualdrapa de marciales adornos" (Palma: 2004, 18), sofocando un motín antibolivariano, el comportamiento de Manuela fue un escándalo que, a decir de la moral cristiana de la época, bien mereció el castigo divino que le fue impuesto: la negación de la maternidad. A Manuela se le acusó de ejercer principios 
insanos, no por abandonar a su esposo para convertirse en la amante de Simón Bolívar, sino por intervenir en un ámbito que estaba vedado para las mujeres: la política. Si bien al inicio, en su primera estadía en Lima (1818 - 1822), divulgó los ímpetus libertarios (por los cuales, junto a otras damas limeñas, recibió de San Martín la condecoración de la Orden del Sol), solo al conocer a Bolívar dio rienda suelta a su espíritu, constantemente contrapuesto al pensamiento del padre, español enemigo de los rebeldes, y a la frialdad de su esposo, médico inglés que le doblaba la edad.

Fue el 16 de junio de 1822 cuando Manuela conoció a Bolívar -quien llegó a Quito después de la victoria conseguida en la batalla de Pichincha- por el General que, meses después, se convertiría en su amigo incondicional: Antonio José de Sucre. A partir de ese día, su vida experimentó nuevos cambios que la llevaron a asumir tareas de espionaje e inteligencia, manejo y protección de los archivos oficiales, investigación y disolución de las conspiraciones contra Bolívar, difusión de las ideas libertarias -con pluma fina y gran erudición- así como también a cabalgar junto a las tropas por las cordilleras de la sierra peruana, a organizar un sistema de sanidad durante la avanzada y permanecer con el ejército, como Teniente de Húsares, hasta la batalla que proclamó la Independencia Americana en los campos de Ayacucho. "Se ha destacado particularmente Doña Manuela Sáenz por su valentía; incorporándose desde el primer momento a la división de Húsares y luego a la de Vencedores, organizando y proporcionando avituallamiento de las tropas, atendiendo a los soldados heridos, batiéndose a tiro limpio bajo los fuegos enemigos; rescatando a los heridos", le escribió Sucre a Bolívar desde el frente de Batalla, el 10 de diciembre de 1824, solicitándole se le otorgue el grado de Coronel del Ejército Colombiano, reconocimiento que no le sirvió de nada a la muerte del Libertador, pues el Gobierno Colombiano la 
desterró por conspiradora ${ }^{5}$, condenándola a una soledad -tan profunda como su grandeza- en Jamaica y, más tarde, en el puerto de Paita, donde murió víctima de la difteria en 1856.

Distinto es el caso de Dolores Veintimilla, poeta quiteña, a quien Ricardo Palma no conoció pero cuyos versos y destino lo conmovieron hasta el punto de dedicarles un ensayo contenido en el libro Dos poetas: apuntes de mi cartera, que fue publicado en 1861 y donde el tradicionista sostiene que los poemas de Dolores son fáciles, armoniosos y profundamente melancólicos porque reflejan un "alma desgarrada". Nacida en 1829, la escritora quiteña casó a los 18 años con el médico Sixto Galindo, quien la llevó a vivir, primero en Guayaquil, y luego en Cuenca. Tentado por un viaje a Centroamérica, el Dr. Galindo dejó a Dolores y a su hijo en Cuenca, y cuidó de enviarles una mensualidad para que subsistieran. Dolores emprendió entonces una vida con una intensa actividad intelectual, promoviendo reuniones culturales y literarias que incomodaron a una sociedad conservadora que no tardó en atribuirle una serie de aventuras y amoríos con el fin de herirla. No obstante, cuando ella escribió la hoja volante Necrología en defensa del indígena Tiburcio Lucero, condenado a la pena de muerte, fue cuando la

5 Como muestra del reparo que le tenían a Manuela, basta citar una carta escrita por Vicente Rocafuerte a Juan José Flores, General del Ejército ecuatoriano y primer Presidente del Ecuador donde deja explícito el peligro que ella representa para la estabilidad del país: "He sentido en el alma la dura necesidad con respecto a la señora Manuela Sáenz; pero si usted estuviera aquí, y viera las grandes esperanzas que fundan en su viveza y audacia, usted hubiera sido el primero en aconsejarnos una medida que diera la política y exige la tranquilidad pública. Madame de Staël no era tan perjudicial en París como la Sáenz lo es en Quito, y sin embargo el gran Napoleón que no veía visiones, y estaba acostumbrado a encadenar revoluciones la desterró de Francia: el Arzobispo Virrey de México desterró de la Capital a la famosa Güera Rodríguez y desde su destierro le hizo una revolución. Las mujeres (de moral relajada) preciadas de buenas mozas y habituadas de las intrigas del gabinete son más perjudiciales que un ejército de conspiradores". Tomado de: DÍAZ, Óscar. El ensayo hispanoamericano del siglo XIX: Discurso hegemónico masculino. Madrid, Editorial Pliegos, 2001, p. 139. 
respuesta social se tornó por demás violenta, al punto que ella no logró resistir tal acoso. Basta citar el accionar de un conocido polemista de la época, quien en tono satírico replicó el texto de Dolores con otra hoja volante a través de la cual buscaba burlarse y acusarla de llevar una vida licenciosa, principios panteístas y nada ortodoxos, y opinar sobre el aspecto formal de sus producciones ${ }^{6}$. El desdichado incidente atormentó a la poetisa hasta el punto de que resolvió quitarse la vida como un acto de evasión, protesta y venganza.

Sobrina de Dolores, Marietta de Veintemilla, a quien Ricardo Palma se refiere en dos cartas, es quizá la figura binacional y más cercana a Manuela por su participación directa en la esfera política y por el silencio al que han sido condenadas sus obras y su propia vida.

Si bien hasta hace poco se desconocían el lugar y la fecha de su nacimiento, gracias al hallazgo realizado por el historiador y genealogista ecuatoriano Fernando Jurado Noboa, se encuentra una partida de nacimiento cuyo contenido confronta las diversas versiones que se tenían sobre su procedencia:

Nació en Lima el 8 de septiembre de 1856, siendo bautizada el 22 de noviembre siguiente de poco más de dos meses en la parroquia del Sagrado Corazón de los Huérfanos con el nombre de María Rosario, en honor a su tía paterna y hermana preferida de su padre. Posteriormente adoptó el nombre de Marietta. En el archivo de Pedro Robles consta que nació en Callao, pero este dato no tiene certificación documental. El dato de que nació a bordo de un barco, es una total fantasía. Su partida de defunción asienta que

6 Tomado de: AGUINAGA, Susana. "La lírica romántica", pp. 91 - 124. En: Historia de las literaturas del Ecuador. Quito, Corporación Editora Nacional/ Universidad Andina Simón Bolívar, 2002, pp. 103 - 104. 
nació en Lima y eso es lo correcto. En Lima habría de vivir 16 años de su existencia, fue pues no sólo su ciudad natal, sino el entorno en el cual vivió su largo destierro de 15 años, pero alentada por el estímulo de toda la intelectualidad de esa capital ${ }^{7}$.

Según refiere el crítico ecuatoriano Enrique Garcés, José de Veintemilla, el padre de Marietta, había viajado a Lima por atender negocios de la Compañía de gas que por entonces iniciaba los ensayos del alumbrado público y, como asiduo espectador de la vida cultural de la capital peruana, al asistir a la presentación de una ópera italiana, quedó prendado de la joven actriz italiana Marietta Marconi. De la unión de ambos nació Marietta ${ }^{8}$ y, acorde a las normas sociales de la época, apenas la familia retornó al Ecuador el matrimonio Veintemilla-Marconi fue oficializado en Guayaquil y, posteriormente, sobrevino la presentación de la familia ante la sociedad quiteña.

El polémico apellido paterno (por los mandatos de Ignacio de Veintemilla) procedía de una familia adinerada, de juristas y militares liberales ${ }^{9}$, quienes habían participado en la vida política del Ecuador. Por el lado materno, en cambio, no se tienen mayores detalles sino los consignados por la mayoría de sus críticos: tanto la abuela como la madre, ambas de

7 JURADO NOBOA, Fernando. Los Veintemilla en la sierra centro norte del Ecuador y en Lima. Quito, Colección Amigos de la Genealogía, v. 157. Serie: pueblos y gentes de frontera, v. 7, 2003, p. 155.

8 GARCÉS, Enrique. Marietta de Veintemilla. Quito, Casa de la Cultura Ecuatoriana, 1949, pp. 35 - 36.

9 Según refiere Garcés, las familias adineradas estaban vinculadas al ejército o a la iglesia, pues el país "no sabía de otra cosa que del presupuesto para mantener militares por montones, los mismos que sostenían o derrocaban dictaduras, casi según el postor. (...) Era preciso también mezclar a la Religión en todos estos espeluznantes dramas de las gentes verdaderamente intoxicadas por el desorden de la administración pública" (23). 
nacionalidad italiana, estuvieron vinculadas al quehacer artístico a través de la compañía de ópera.

El matrimonio Veintemilla-Marconi tuvo cuatro hijos, dos de los cuales fallecieron a edad temprana, antecediendo con pocos años a la muerte de los progenitores. Huérfanos de ambos padres, tanto ella como su hermano Ignacio, fueron apadrinados por sus tías (Rosario y Rafaela $^{10}$ ) y por su tío Ignacio.

Pero el giro que permitió su incursión en la escena política ecuatoriana se dio en marzo de 1882, cuando su tío Ignacio se proclamó por segunda vez dictador del Ecuador, ocasionando el golpe revolucionario liderado por uno de sus hombres de confianza: el General Cornelio Vernaza, entonces Ministro de Guerra. Como Ignacio de Veintemilla se encontraba de visita en Guayaquil, Marietta velaba en la capital ecuatoriana por los intereses del Presidente y fue así que, en la madrugada del 26 de marzo, tuvo la primera confrontación con el Gral. Vernaza, quien había movido al ejército para destituir a Veintemilla. Esta sería la primera de las varias revueltas políticas en la que se vería inmersa hasta el 10 de enero de 1883, cuando fue tomada prisionera.

Llegó a ser la Gobernadora del Estado con más firmeza que el papá. (...) Ella ha sido el alma de la resistencia en Quito; ella sola ha gobernado estas provincias en la ausencia del Dictador. (Los Principios, 10 de febrero) (19) ${ }^{11}$.

10 Según refiere Nancy Ochoa, las tías Rosario y Rafaela, permanecen en prisión junto a Marietta, entre enero y agosto de 1883, y la acompañan al destierro en Lima donde Rafaela "fundó la orden de «Agustinas, hijas del Santísimo Salvador», y su proceso de beatificación fue iniciado por la Iglesia Católica en 1989". Tomado de: OCHOA, Nancy. Marietta de Veintemilla. Pensamiento fundamental. Quito, Campaña Nacional Eugenio Espejo por el libro y la lectura Corporación Editora Nacional - Universidad Andina Simón Bolívar, 2007, p. 37.

11 Tomado de CUNHA-GIABBAI DA, Gloria. El pensamiento de Marietta de Veintemilla. Quito, Ediciones del Banco Central del Ecuador, 1998. 
Pasó ocho meses en prisión, agobiada por las amenazas y afrentas de los restauradores. Dedicada a la lectura, sobre todo a las historias de Francia y de Roma, Marietta resiste hasta septiembre de ese año y es liberada gracias a las gestiones diplomáticas y de la gente allegada a la familia Veintemilla. Como el gobierno en funciones deseaba evitar cualquier revuelo originado por la familia del dictador, notifica a Marietta la orden de abandonar el país, y ella parte hacia Lima. En la capital peruana, Marietta se sostiene económicamente dictando clases de piano y de canto, sin descuidar su vinculación con los acontecimientos políticos del Ecuador. De ahí que en 1890, año en el que publica Páginas del Ecuador ${ }^{12}$, ella busque retomar la presencia política de los Veintemilla, enviando a Guayaquil ejemplares de su libro con su hermano Ignacio; y distribuyéndolos entre intelectuales latinoamericanos de reconocido prestigio con los que mantenía contacto como Ricardo Palma, Rubén Darío, Juan Manuela Gorriti, entre otros.

Posteriormente regresa al Ecuador y en Quito se dedica al cultivo de productos, -de cuya venta lograba mantenerse- y a la intervención en la vida política. No deja de escribir y por su gran curiosidad de inquietud intelectual fue la primera mujer que, el 10 de febrero de 1907, dio una intervención magistral en la Universidad Central del Ecuador. Como sus alcances políticos buscaban el retorno de su tío Ignacio al poder, desde enero del mismo año planeó derrocar a Alfaro e hizo un viaje clandestino a Tulcán donde, al parecer, se reactivó un antiguo paludismo que venía tratándose en Quito, y que acabó con su vida el 11 de febrero de 1907.

12 VEINTEMILLA DE, Marietta. Páginas del Ecuador. Lima: Imprenta Liberal de F. Macías y $\mathrm{C}^{\mathrm{a}}, \mathrm{I} 890$. 
Y grande sería su ausencia para que un escritor de oposición a los Veintemilla reconociera a Marietta como la única página brillante de la Dictadura, y describiera de manera contundente el cortejo que la acompañó al cementerio: "Y los funerales de Marietta, sin embargo, fueron como en el Ecuador no los ha habido jamás para una mujer. Sin sentirlo, sin advertirlo nadie, fueron propiamente los de un General de la República, como si de suyo reconociera la nación la innegable superioridad de la valerosa Mayasquerita"13.

Como hemos referido, la relación que vinculó a Ricardo Palma con Marietta fue la publicación de su libro Páginas del Ecuador, en el que ella plasma su visión sobre la historia y la política ecuatorianas desde su fundación en 1830. Los comentarios de Palma al libro son favorables y resaltan, por un lado, la belleza y valentía de la autora, y, por otro, el gran porvenir de Marietta en el ámbito literario por el estilo que la caracteriza. Sin embargo, también están presentes las recomendaciones sobre los temas a abordar, temas donde el alma de mujer pueda alcanzar mayor desarrollo, es decir, reproducir el rol femenino del proyecto civilizatorio del siglo decimonónico:

Me ha honrado U. con el obsequio de un ejemplar de su libro Páginas del Ecuador, y manifestándome deseo de conocer mi juicio sobre su producción literaria. (...) Líbreme Dios de entrar en el campo de apreciaciones históricas y políticas sobre un país cuyos sucesos contemporáneos conozco solo en síntesis general, y no con amplitud de pormenores. (...) Ha escrito U., Marieta amiga, un verdadero libro de partido y de polémica. (...)

13 Según refiere la misma Marietta, al regimiento de Tulcaneños (oriundos de la ciudad de Tulcán, ubicada en la frontera con Colombia), partidarios de Veintemilla, que luchaban contra los Restauradores, se los llamaba Mayasqueros por el nombre de la montaña que existe en tal ciudad: Mayasquer; y como Marietta dirigió a tales soldados, la nombraron la Mayasquerita. 
La aspiración natural de todo el que maneja una pluma es la de imponerse al lector, obligándolo a que, una vez propiciada la lectura, no deje el libro de la mano y sienta avidez por llegar al término. De mí sé decir que he devorado con deleite las Páginas del Ecuador. El estilo de U. es claro y elegante; y narra $U$. los hechos con lógica y con encantadora sobriedad, sin que la sobriedad perjudique en lo menor a la animación del relato. (...) Cuando exhibe $U$. el retrato moral de algunos de los personajes culminantes en su obra, paréceme estar leyendo páginas dictadas por Tácito o Gernivus. La persona de García Moreno, por ejemplo (...). Si el retrato que usted pinta con tan vivo colorido es copia fiel, como a mí me parece, enorgullézcase de él la literata. Esas son plumadas magistrales.

Llámame también la atención en el libro de U. el que, apartándose de las preocupaciones propias de su sexo, no abrigue, en punto a creencias religiosas, la fe del carbonero, exhibiéndose no como creyente ciega sino como racionalista osada. (...). ¿Aspira U. acaso a que en su patria la excomulguen, ya que en las postrimerías del siglo XIX las excomuniones andan bobas, como acaba de hacerse aquí con Clorinda Matto, que, sin ser libre pensadora como Ud., ha sido víctima escogida para intimidar a los seres del sexo bello que se sintieran tentados a huir del confesionario y desertar del coro de adoratrices? (...) Decididamente, Marietta, hay en $U$. muy varoniles bríos, y quien no la conozca ni por retrato la supondrá, físicamente, mujer robusta, vieja, hombruna y hasta con pelos en la barba y no la joven de palidez romántica, de aire risueño siempre, y que en la vida social tiene todas las graciosas y espirituales delicadezas de niña mimada.

Escriba U., Marietta, se lo aconsejo, (...) pero apártese de la política militante, amiga mía, que la política es una hoguera en la que quien no se quema se tuesta. No me gusta ver sus alas de mariposa gentil en vecindad con el humo caliente de las llamas. 
iCuánto deploro, que libro tan bien hecho, tan bien escrito, como el de U., sea libro de combate! Yo la querría a U. más mujer y menos batalladora (...).

Lima, octubre 4 de $1890^{14}$.

Parece normal que dados los parámetros de la época la incursión de Marietta en temáticas políticas acuse críticas que encuentran en su estilo bríos varoniles, sin embargo, cabe mencionar que aquellos comentarios engrosaron la comidilla de la época sobre si Marietta era la verdadera autora del libro. El mismo Ricardo Palma en una carta dirigida a Francisco Sosa ${ }^{15}$, el 15 de marzo de 1991, le comenta sus dudas al diplomático mexicano, aludiendo a que la prensa ecuatoriana, adversaria a Marietta, afirmaba que el libro lo habría escrito el poeta peruano Carlos Amézaga.

Y es que tanto Manuela como Marietta son dos personajes que escapan al corsé que el proyecto civilizatorio del siglo XIX tenía para las mujeres, mientras Rosa y Dolores se ajustan al perfil instituido a partir de la dicotomía público/privado: los ámbitos de la política eran competencia masculina y las mujeres debían permanecer alejadas de ella.

Esta concepción limitada yace en el origen de la formación y estructuración de las nuevas repúblicas, pues se acepta la ubicación natural de los hombres en la esfera pública y de las mujeres en la esfera privada, relacionándolas a estas últimas con la naturaleza por la reproducción, crianza de los hijos y cuidado de la familia mientras a los hombres se los identifica con la generación de la cultura. Al respecto, Simone de

14 Tomado de: PALMA, Ricardo. Epistolario General (1846-1891). Lima: Universidad Ricardo Palma - Editorial Universitaria, Vol. III, 2005.

15 En aquella carta, Palma refiere además que Clorinda (Matto de Turner) y Mercedes Cabello eran las primeras en sostener que el libro no era de Marietta. 
Beauvoir hace hincapié en una frase esclarecedora: "No es solo dando vida sino arriesgando la vida, que el hombre se eleva por sobre el animal; es por eso que la humanidad ha acordado la superioridad no para el sexo que procrea sino para aquel que mata"16. La dominación y el sometimiento de la naturaleza, ya sea por la fuerza o por el conocimiento, alimentan la noción de cultura pensada y gestada desde y por los hombres. Las mujeres, como sostiene Yuval-Davis, son construidas en dichos proyectos como "símbolos de la esencia nacional, unidad y emancipación, así como guardianas de frontera de la diferencia étnica, nacional y racial. Estas construcciones de la condición de mujer son muchas veces empleadas como recursos para las relaciones nacionales de dominación y resistencia" ${ }^{17}$.

Y tal es la presencia de estas construcciones que aun cuando figuras como Manuela y Marietta se hayan rebelado contra los roles impuestos en el siglo XIX, ellas mismas no dejan de lado las dicotomías de la civilización/naturaleza-barbarie y de lo público/privado, cayendo así en grandes contradicciones. Y es que la necesidad de justificar sus comportamientos evidencia posiciones ambivalentes porque fluctúan entre el llamado a actuar -del que están totalmente convencidas- en un ámbito de hombres y la necesidad de justificar sus acciones ante ellos, por ser quienes deciden sobre el destino de la nación.

Muestra de ello son las referencias irreconocibles que se observan en los textos de Manuela y Marietta sobre la condición

16 YUVAL-DAVIS, Nira. Género y nación. Lima, Flora Tristán, 2004, p. 20.

17 YUVAL-DAVIS, Nira. Op. Cit., p. 171. Al respecto, Yuval-Davis añade que aunque la paternidad decide sobre la membresía nacional o religiosa, las mujeres son quienes dan a luz a la colectividad. Lo que conlleva que, además de ser reproductoras biológicas de la nación, sean reproductoras culturales, “a quienes se les encarga la tarea de ser guardianas de la cultura”. De ahí que representen símbolos a los cuales se apela tanto en contextos de dominación como de resistencia. 
femenina, pues, por un lado, participan en la política del país y de la región; y, por otro, no pueden eludir los roles que le fueron impuestos por la sociedad patriarcal.

De ahí que compartan las reflexiones de Ricardo Palma sobre la promoción de la participación de la mujer en ámbitos culturales, destaquen la capacidad femenina para incursionar en ciertos campos vinculados a la vida pública (como la educación o las letras) y reconozcan que el destino de las nuevas naciones recaía en el quehacer de los hombres; $y$, al mismo tiempo, se alejen y cuestionen al tradicionista con sus propias acciones, sentando así un precedente sobre la auto-interpelación de la mujer como un sujeto de derechos que abre caminos para el reconocimiento de la participación de las mujeres en otros espacios.

"Descender a una lóbrega cárcel para encontrar en ella a una mujer que respiró el aire de momentánea soberanía ${ }^{18}$; a la que cambió bruscamente las suntuosidades de un palacio por las horribles miserias de un calabozo, es materia siempre digna de estudio", escribe Marietta al momento de relatar su cautiverio y, en aquella evocación, la soberanía que invoca no es la del régimen, sino y, sobre todo, la de sí misma, liberada del corsé femenino.

Los legados de Manuela y Marietta son la fuerza con la que sus voces se rebelan ante las condiciones impuestas y son, además, las huellas que dejan en el texto una resonancia que se mantiene a pesar del silencio que aún cobija a sus nombres y a sus obras. Ellas son las mariposas cuyas alas se abrigaron con el fuego sin quemarse.

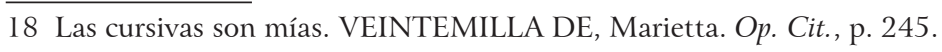




\section{Bibliografía}

AGUINAGA, Susana. La lírica romántica, pp. 91 - 124. En: Historia de las literaturas del Ecuador. Quito, Corporación Editora Nacional/Universidad Andina Simón Bolívar, 2002.

CUNHA-GIABBAI DA, Gloria. El pensamiento de Marietta de Veintemilla. Quito, Ediciones del Banco Central del Ecuador, 1998.

DÍAZ, Óscar. El ensayo hispanoamericano del siglo XIX: Discurso hegemónico masculino. Madrid, Editorial Pliegos, 2001.

FALCONÍ, Gabriela. La voz detrás del silencio. Interpelación al discurso oficial del siglo XIX desde Páginas del Ecuador de Marietta de Veintemilla. Lima, Tesis para obtener el grado académico de Magíster en Literatura Peruana y Latinoamericana, Universidad Nacional Mayor de San Marcos, 2013.

GARCÉS, Enrique. Marietta de Veintemilla. Quito, Casa de la Cultura Ecuatoriana, 1949.

HOlguín CALlO, Oswaldo. Páginas sobre Ricardo Palma. Lima, Universidad Ricardo Palma, 2001.

JURADO NOBOA, Fernando. Los Veintemilla en la sierra centro norte del Ecuador y en Lima. Quito, Colección Amigos de la Genealogía, v. 157. Serie: pueblos y gentes de frontera, v. 7, 2003.

OCHOA, Nancy. Marietta de Veintemilla. Pensamiento fundamental. Quito, Campaña Nacional Eugenio Espejo por el libro y la lectura - Corporación Editora Nacional - Universidad Andina Simón Bolívar, 2007.

PALMA, Ricardo. Tradiciones Peruanas. Lima, Universidad Ricardo Palma La República, Tomo VIII, 2004.

- Epistolario General (1846-1891). Lima: Universidad Ricardo Palma - Editorial Universitaria, Vol. III, 2005.

VÁSCONEZ, José Miguel. El Ecuador en las Tradiciones de Ricardo Palma, pp. 285 - 323. En: Instituto Ricardo Palma. Aula Palma VI. Lima, Universidad Ricardo Palma, 2007. 
VEINTEMILLA DE, Marietta. Páginas del Ecuador. Lima: Imprenta Liberal de F. Macías y C $C^{\mathrm{a}}, 1890$.

YUVAL-DAVIS, Nira. Género y nación. Lima, Flora Tristán, 2004. 